\title{
O processo de design pelo olhar da complexidade: uma oportunidade de ressignificação pelas estratégias ${ }^{1}$
}

\section{The design process from the perspective of complexity: an opportunity for reframing through the strategies}

\author{
Danielle Difante Pedrozo, UFSM. \\ danielle.pedrozo@ufsm.br \\ Ione Maria Ghislene Bentz, UNISINOS. \\ ioneb@unisinos.br
}

\begin{abstract}
Resumo
Este artigo apresenta uma reflexão transdisciplinar pela perspectiva da teoria da complexidade com o objetivo de incentivar uma abertura para a renovação de práticas projetuais, principalmente no que diz respeito às metodologias de design. Para isso, por meio de revisão bibliográfica, pauta sua discussão ancorada na proposta de reorganização de conhecimento pela "ciência nova" de Edgar Morin. No que se refere ao design, identifica processos projetuais capazes de responder aos desafios da complexidade e fundamenta noções como estratégia e programa, consideradas essenciais para o pensar e o agir projetual. A sua contribuição indica que é possível projetar com as ideias vindas da complexidade, desde que o designer tenha em mente o permanente arranjo e mutação dos ecossistemas considerados. Além disso, considera que uma atitude crítico-reflexiva é necessária para que o processo de projeto seja uma instância de operação de inteligência, de sensibilidade e de produção de conhecimento.
\end{abstract}

Palavras-chave: Ciência nova, Estratégia, Programa, Complexidade, Design

\begin{abstract}
This article presents a transdisciplinary discussion from the perspective of complexity theory in order to encourage an opening for renewal of design practices, especially regarding design methodologies. For this, through bibliographic review, its debate is based on the proposal for the "new science" reorganization of knowledge by Edgar Morin. With regard to design, it identifies design processes capable of responding to the challenges of complexity and provides fundamentals for notions like strategy and program, considered essential for design thinking and acting. Its contribution signals the possibility of designing from ideas coming from complexity, as long as the designer has in mind the permanent arrangement and mutation of the ecosystems considered. In addition, it considers that a critical-reflexive attitude is needed for the design process to be an instance of functioning of intelligence, sensitivity and knowledge production.
\end{abstract}

Keywords: New Science, Strategy, Program, Complexity, Design

\footnotetext{
${ }^{1}$ O presente trabalho foi realizado com apoio da Coordenação de Aperfeiçoamento de Pessoal de Nível Superior Brasil (CAPES) - Código de Financiamento 001
} 


\section{Introdução}

O paradigma da complexidade tem oferecido um conjunto de reflexões significativas para a crítica às práticas de pesquisa cientifica até então dominantes, com repercussões na pesquisa em design. Enraizado na física de Prigogine (1996), esse paradigma reconhece a complexidade do real que concebe "o cosmos não como uma máquina perfeita, mas como um processo em via de desintegração e de organização ao mesmo tempo", e que vê o mundo como "fenômeno de autoeco-organização extraordinariamente complexo que produz autonomia" (MORIN, 2005, p. 4446). Organiza-se em espaços de assimetria e dissimetria, de certeza e de incerteza, de reunir e de separar, de globalizar e de individualizar, ou seja, opera um tipo de pensamento que tece em conjunto os múltiplos na singularidade.

Segundo Morin e Le Moigne (2000), os princípios dialógico, recursivo e hologramático que pautam o pensamento complexo encarregam-se da unificação das forças antagônicas, da compreensão inter-recorrente de causas e efeitos e da materialização da totalidade que existe pela parte que, contudo, só existe pelo todo, em um movimento de auto-replicação. Nessa perspectiva, os sistemas organizam seu fechamento e autonomia na e pela abertura; o movimento que deles decorre se faz do desequilíbrio nas leis da organização da vida e que nele mesmo se recupera ou compensa; o que resulta no fato de que a inteligibilidade se encontra no próprio sistema. Essa compreensão marca o que Morin (2005) chama de nova ciência ou de ciência da vida, no sentido de ser multidimensional, de integrar as áreas e de, ao mesmo tempo, manter a sua unicidade, de tal sorte que abra novos horizontes para fazê-la avançar. É nesse contexto que se destacam conceitos como transdisciplinaridade, complexidade e autopoieses. Essas proposições poderiam ser relevantes para a ressignificação dos processos de projetação em design.

Assim, inspirado nesse enquadramento, a área de design se perguntaria sobre os benefícios que daí poderiam advir para o pensar e o agir projetual, nos termos dos dispositivos sistêmicos. A forma como o conhecimento é organizado precisa ser transformada por uma "nova ciência" que deve ser transdimensional e, ao mesmo tempo, deve integrar as áreas em seu ideal de unicidade e de abertura para o novo. Nesse sentido, estudiosos da área, como Alexou, Johnson e Zamenopoulos (2009) também avançam suas pesquisas na complexidade, ao apontar que o design como disciplina caminha para ser um estudo obrigatório também para a ciência, por considerá-lo um processo fundamental para compreender, criar e gerenciar os sistemas complexos.

Entretanto, a presente reflexão nasce pela motivação de que o design pode encontrar nas ideias de Edgar Morin uma possibilidade de oxigenar as suas práticas projetuais, principalmente no que diz respeito ao percurso projetual, ou seja, às suas metodologias. Nesse contexto, entre os conceitos que podem contribuir para esse esforço metodológico estão o de estratégia e de programa que, pelo viés da complexidade, podem estimular os designers a repensarem seus métodos. Pautar essa discussão é o principal objetivo deste artigo.

\section{A teoria da complexidade e sua conexão com o design}

A ciência clássica dominante fragmentou os conhecimentos e superespecializou os profissionais; baseou-se em verdades absolutas e definiu a sua realidade a partir de uma lógica de clareza e distinção. A matéria por muito tempo ocupou uma posição central e qualquer outro tipo 
de manifestação fenomênica humana, como a imaginação e a criação, por não serem logicamente explicáveis, eram sempre desconsideradas como relevantes cientificamente. Ao mesmo tempo, os cientistas sabiam que, sem esses movimentos de permanente crítica, na confluência de diferentes paradigmas científicos, o progresso da ciência não teria sido possível.

Não tardou para que os efeitos dessa ciência começassem a aparecer. Grandes avanços foram concebidos, mas os cientistas mostravam-se incapazes de dominar as consequências de suas descobertas. Morin (2005) chamou de "mutação inaudita no conhecimento", a síndrome que afetou das mídias às universidades, na qual cada vez mais o conhecimento era produzido para não ser refletido e nem discutido pelas mentes humanas. O próprio design, com a proposição de seus modelos e metodologias tão precisos e funcionais, acabou por incentivar um comportamento passivo dos seus estudantes, que não mais precisavam refletir sobre eles, apenas praticar e tornarem-se cada vez mais habilidosos no seu fazer. Essa seria a inteligência cega que não consegue conceber o elo que une todas as coisas, que fragmentou o tecido complexo das realidades e que fez crer que o seu corte arbitrário do real fosse o próprio real, como aponta Morin (2005). Nessa compreensão de ciência, não sobrou espaço para o sujeito, que foi colocado à parte, isolado, como se, a partir de uma câmara asséptica, observasse o mundo e seus fenômenos, completamente dissociado dele.

Ressalte-se que os princípios da complexidade sempre estiveram presentes, mesmo sem serem nomeados. Eles já eram pensados e praticados pelos desacreditados da ciência, por aqueles que se permitiam conectar outros tipos de conhecimento às suas práticas criativas, como por exemplo, os sábios, os artistas e os artesãos. O que essas figuras de certa forma já intuíam, é que a complexidade e a realidade que nos é dada a conhecer compartilham os atributos de dinamismo e transformação, onde nada é definitivo, nem mesmo as verdades afirmadas como tal. Tal entendimento significa que o conhecimento está aberto para ser superado o tempo todo.

Dessa forma, ao trazer a complexidade para a centralidade da discussão, num esforço de abordar a "ciência da vida" pelo olhar do design, se torna quase impossível não conectá-la à metodologia, à epistemologia e até mesmo à ontologia, em uma perspectiva aberta e coerente, constituindo assim um discurso multidimensional. Trabalhar com essa perspectiva demanda uma metodologia aberta e específica, que seja capaz de delinear as unidades e as relações sistêmicas complexas.

Ao recuperar um pouco da história das teorias de metodologia no design, que foi significativamente marcado pelo "Design Methods Movement" (Movimento dos Métodos de Design) entre as décadas de 60 e 70, encontram-se autores que se destacaram, como Nigel Cross (1993, 2008) e Chris Jones (1992). Nos seus textos revisados, percebe-se que ambos apresentavam os seus métodos ainda bastante estruturados e baseados na lógica industrial. Os dois dividiam o processo de projeto em três etapas: análise, síntese e avaliação (CROSS, 2008); e divergência, convergência e avaliação (JONES, 1992). Já Cross (2008), assim apresentou seus dois modelos de design: o descritivo, definido por ele como processo convencional de design, no qual a atividade mais importante do processo é a descrição do artefato para a produção; e o prescritivo, que busca entender o problema na sua totalidade, considerando os inputs do mundo externo e utilizando como output a comunicação da solução alcançada. 
Jones (1992), ao contrário de Cross (2008), trazia uma visão mais aberta sobre os problemas e os processos de design. Começava a refletir sobre a consciência do designer em projetar num sistema complexo e no seu dever de estar ciente de todo o ciclo de vida do produto. Isso mostra uma preocupação com a responsabilidade social dos projetos, o que, na atualidade, se tornou tema central de discussão. Ainda no seu texto, ele comparava o designer com um explorador em busca do tesouro, o qual ilumina a real função do método que é, para ele, reduzir ao máximo a área de exploração do problema. Com isso, o que determinaria o método era o grau de inovação e de imprevisibilidade do projeto, e, em seu processo, ele decompôs o método para depois reintegrálo ao nível de sistema. Nota-se que o autor começou a reconhecer uma necessidade de abertura, mas de forma muito discreta e controlada.

Cross (1993) trouxe ainda algumas críticas voltadas aos 'metodologistas' de design que, desde as suas primeiras proposições, buscaram estabelecer uma distinção entre design e ciência. Alguns autores, como: Alexander (1973), Gregory (1966) e Simon (1999), faziam essa distinção a partir de uma visão positivista, ao se basear em conceitos considerados ultrapassados de método científico e epistemologia. Eles defendiam que os cientistas se ocupariam em identificar os componentes das estruturas existentes e os designers de moldar os componentes das novas estruturas. Entendiam o método científico como um padrão de comportamento de resolução de problemas, enquanto método de design seria um padrão de comportamento empregado na invenção de coisas. Consideravam a ciência como analítica e o design como construtivo. Enfim, essas eram as concepções vigentes naquele momento. Nas décadas seguinte (70, 80 e 90), as teorias sobre metodologias no design continuaram a se desenvolver, principalmente por meio da proposta de modelos dos processos de design e com um interesse cada vez maior pela tecnologia e pela inovação social.

A recuperação desse pequeno trecho da história das teorias de metodologia no design, certamente não exaustivo, serve como uma pequena amostra para contextualizar o que esse artigo busca fazer, ao abrir, mais explicitamente, os caminhos da complexidade na formulação metodológica. Não é interesse deste texto distinguir o design da ciência, muito pelo contrário, pela proposta da "ciência da vida" de Morin se antevê um caminho para propor uma reorganização do conhecimento de maneira mais integrada. Essa reflexão também parte do entendimento de que toda a atividade de design pressupõe um processo de projeto e esse processo é uma instância de operação de inteligência e de produção de conhecimento. Sua natureza é híbrida, pois esse processo é perpassado por reflexões teóricas indutivas, dedutivas, empíricas e abdutivas. Além disso, propõe-se aqui que o processo seja entendido como percurso, palavra vinda do latim 'percursos' que significa 'ação de percorrer'. O termo percurso parece adequado para designar processo, pois carrega consigo uma noção de mudança de estado, de movimento, o que caracteriza um processo de design complexo. Esse percurso, se tratado pelo olhar da complexidade, pode ser guiado por um 'programa' e enriquecido pelas 'estratégias'. A ação projetual não envolverá mais usuários específicos, e sim sujeitos (dotados de vários papéis sociais) e que estão em permanente relação com os objetos, dentro de um sistema, que, por sua vez, é parte de um ecossistema maior. Essa são as principais noções que serão aprofundadas abaixo pela perspectiva transdisciplinar de Morin.

\section{As estratégias da vida: a instância do conhecimento e da ação}


Na elaboração do seu entendimento de estratégia, Morin (2015b) não só explora teoricamente a instância da ação, como também a do conhecimento. Nessa segunda instância, a do conhecimento, apresenta aos seus leitores as estratégias cognitivas. A definição de estratégias cognitivas deriva do pensamento cognitivista praticado por Simon (1999), autor de forte influência no design, que considera o aparelho neurocerebral como um general problems solvers que dispõe de dupla memória, uma genética e outra pessoal. Para esse autor, o cérebro possui altas competências para tratar os dados dos sentidos e aptidões estratégicas, para resolver os mais variados problemas, de modo a atingir múltiplos fins. Nesse sentido, Morin recupera esses termos na ordem de racionalidade que funda o pensamento complexo. Tal racionalidade responde aos princípios da dialogia, da recursividade e do holograma, respectivamente: (a) mantém a multiplicidade na unidade e vice e versa, que é capaz de associar dois termos ao mesmo tempo complementares e antagônicos; (b) considera que os produtos e os efeitos são, ao mesmo tempo, causas e produtores do que os produz; e (c) compreende que a parte está no todo e o todo está na parte, (MORIN, 2005).

É nesse paradigma que estratégia e programa estão compreendidos. Se ação e conhecimento dão forma à estratégia, ambas não podem ser dissociadas. Assim, a ação projetual e as operações cognitivas coocorrem na definição das estratégias em design. Para Morin (2015a), é a inteligência que articula a estratégia no conhecimento e na ação, já que diante de uma realidade complexa, feita de multiplicidade de fenômenos e de riscos e incertezas, as estratégias visam a harmonizar o antagônico e múltiplo e a simplificar e complexificar o conhecimento. Há estratégias no processo de simplificação e de complexificação as quais se combinam e se alternam em movimentos de dupla exigência, simultaneamente contraditórias e complementares, (MORIN, 2015a), ao trabalhar, na construção do conhecimento, o estável e o determinado, o certo e o incerto e o claro e o ambíguo. O conhecimento e a ação devem saber, simultaneamente, combater e utilizar a incerteza a seu favor. Essa sabedoria implica a escolha das estratégias para atingir os objetivos propostos.

A definição de estratégia relaciona-se diretamente com a definição de programa, pois todo o processo vivo constitui um composto variável de estratégia e programa. Para Morin (2015a, p. 250), "programa é algo inscrito previamente, é um conjunto de instruções codificadas que, quando aparecem as condições específicas da sua execução, permitem o desencadeamento, o controle, o comando por um aparelho de sequências de operações definidas e coordenadas para alcançar certos resultados". Já a estratégia, similar ao programa, comporta o desencadeamento de sequências de operações coordenadas, mas dele difere por não se basear somente em decisões iniciais de desencadeamento, mas, também, em decisões sucessivas, tomadas no desenrolar da situação, o que pode provocar modificações em todos os âmbitos das operações previstas. Esse tipo de estratégia é inspirador para um processo de design, já que incentiva uma atitude astuta do designer para servir-se dos fatos inesperados, do acaso, para propor ações em resposta ao que se apresenta durante o processo. Ao invés de prender-se a suas expectativas já configuradas e bloquear ou cancelar um processo, o designer, diante das eventualidades, poderá usá-las em seu benefício. 
O programa e a estratégia recorrem um ao outro e a complexidade dos programas, longe de eliminar qualquer estratégia, multiplica as possibilidades de suspender o programa em proveito de uma iniciativa estratégica. $O$ desenvolvimento das estratégias potencializa a utilização das sequências programadas na mesma proporção em que favorece a escolha de estratégias nos momentos mais decisivos. Assim, o êxito de uma estratégia inventiva cria as condições de estabilidade e de proteção que permitem repeti-la, e, tornada repetitiva, rotineira, converte-se em um programa. Dessa forma, para Morin (2006), os programas podem nascer de uma estratégia, mas não o inverso. A escolha entre um programa ou estratégia depende de uma dada estratégia anterior, a cognitiva, que vai definir se economiza ou não a estratégia.

Este paradigma de compreensão aporta ao pensar e ao fazer do design importantes estímulos. O programa, por exemplo, pode alicerçar qualquer metodologia que oriente o fazer projetual do design. Nas práticas projetuais, a metodologia já está pré-estabelecida, seja por etapas, ciclos ou indicações em fluxo, de acordo com o paradigma adotado. Entretanto, na perspectiva aqui adotada, os programas são tensionados pelas estratégias que, por sua vez, não são algo que se acoplam ou se desenham, anterior ou posteriormente aos resultados. Elas são significadas e ressignificadas na relação programa/estratégia que ocorre ao longo das ações do processo projetual. Nessa perspectiva, um planejamento estratégico tradicional, se aproximaria mais da noção de programa do que de estratégia, pois ele já traz definidas as ações que considera estratégias. Contudo, para Morin (2015a), a estratégia não é um meio para agir, mas sim "a arte da ação viva", já que acredita que o novo não é trivial e não pode ser estabelecido antecipadamente.

Ao pensar estratégias, esse paradigma inspirado na complexidade dá relevância a noção de sujeito, que Morin (1996) define como noção "biológica", no sentido de uma lógica própria do ser vivo que permite conceber a sua autonomia relacionada com as noções de dependência e autoorganização. Para o ele, ser sujeito é situar-se no centro do seu mundo para computá-lo e computar-se, é poder operar uma disjunção ontológica entre o Si e o não Si, e assim constituir e instituir o auto-ego-centrismo que é a base fundamental da subjetividade (MORIN, 2016). Esse entendimento é relevante, pois é assim, por esse o ponto de vista complexo, que supõe o mundo e reconhece o sujeito. Morin (2005) defende a inserção do sujeito na ciência e explicita a relação entre sujeito e objeto de conhecimento por meio de um metaponto de vista. Esse metaponto de vista só é possível, se o observador-conceptor se integram na observação. Sendo assim, ele coloca ambos de maneira recíproca e inseparável: o mundo só pode aparecer como tal (horizonte de um ecossistema de ecossistema) para um sujeito pensante, último desenvolvimento da complexidade auto-organizadora. Quando uma área como o design começa a se apropriar desses entendimentos, deve ter em mente o tipo de relação que se estabelece entre o sujeito e o objeto, para poder internalizar e agir com esses conceitos em seus projetos:

O sujeito e objeto aparecem assim como as duas emergências últimas inseparáveis da relação sistema auto-organizador/ecossistema. O mundo está no interior da nossa mente, que está no interior do mundo. Sujeito e objeto neste processo são constitutivos um do outro. (MORIN, 2005, p.39)

Essa máxima revela uma tendência que tem surgido no design contemporâneo, na qual o foco passa dos produtos (objetos) para as relações processadas em e pelos processos. Essas mudanças decorrem das articulações e conexões produzidas pela reorganização do conhecimento e mudança 
de paradigma. Nessa perspectiva, a estratégia necessita de lucidez na sua elaboração e na sua conduta, pelo jogo de iniciativas e de responsabilidades, ou seja, pelo pleno emprego das competências individuais e das qualidades do sujeito. Sendo assim, tanto o designer quanto os demais envolvidos em um projeto são parte constituintes, são sujeitos em relação que compartilham seus valores e intenções.

Manzini (2017), designer, pesquisador italiano e autor referência em design para inovação social, apesar de não revelar a sua filiação, também trabalha com a noção de sujeito, um sujeito como protagonista, imerso na sua vida diária e que participa de vários diálogos, sendo um nó em várias redes e um ator em várias formas sociais. Este sujeito ressignifica seu projeto de vida, dando origem a novos comportamentos colaborativos no modo de viver e de produzir dos quais emerge uma onda de inovação social. Para o autor, o design deve estar voltado para questões complexas (problemas), em um sistema que não separa o mundo físico e biológico do mundo social. Afirma que os artefatos de design, ao se deslocar de produtos para processos e relações, retomam a definição de design como "um processo exploratório que tem por objetivo criar novos tipos de relações de valor entre diversos atores em uma mesma configuração sociomaterial" (MANZINI, 2017, p.53).

Nota-se que nos estudos das relações que se dão entre o ser humano, a sociedade e a empresa, esses componentes não são máquinas triviais, pois os processos que expressam as relações entre eles são autopoiéticos ${ }^{2}$. Morin (2015a) vê o mundo físico como um jogo que necessita de um elemento essencial que é o jogador (ator-sujeito) e quando ele 'joga' é que a estratégia se aproxima do seu potencial supremo: a invenção. Em um processo de design, o jogador é o projetista que, ao buscar entender a dinâmica de um sistema, pode aprimorar os seus processos e, por consequência, as suas descobertas.

Segundo Morin (2015a):

A estratégia supõe a aptidão do sujeito para utilizar de modo inventivo e organizador, para a sua ação, os determinismos e os riscos exteriores: podemos defini-la como o método de ação próprio de um sujeito em situação de jogo, no qual, a fim de realizar os seus fins, ele se esforça por suportar ao mínimo e de utilizar ao máximo as regras (imposições, determinismos), as incertezas e os acasos do jogo. (MORIN, 2015a, p.253)

Nessa passagem, Morin (2015a) aproxima a estratégia de jogo, jogo que encontra no ecossistema condições ideais para acontecer. Para o autor, o jogo é uma condição que obedece a regras e suporta eventualidades, portanto comporta riscos e probabilidades, visando a obter um dado resultado. Os ecossistemas apresentam naturalmente as condições do jogo, uma vez que são simultaneamente deterministas (regras do jogo) e aleatórios (incertezas do jogo). Compreendido ecossistema como "conjunto das interações no centro de uma unidade geofísica determinável contendo diversas populações vivas", ele compõe uma unidade complexa organizadora, ou seja, um sistema (MORIN, 2015a, p.36). O sistema, portanto, constitui "uma unidade global organizada de inter-relações entre elementos, ações, indivíduos” (MORIN, 2016, p.131), unitários e globais simultaneamente.

\footnotetext{
${ }^{2}$ Maturana e Varela (1980) definem autopoiético como um sistema capaz de se reproduzir autonomamente, pelo princípio de inteligibilidade e auto-organização, sejam os próprios componentes, sejam as relações que unem o conjunto.
} 
Em síntese, a estratégia se constrói a cada instante de acordo com as situações que se apresentam. As estratégias trabalhadas pelos processos de design respondem à cognição, ao discernir o 'novo' e à ação, ao utilizar esse 'novo'. E é nesse paradigma da complexidade que as noções aqui expostas pretendem fomentar um design sempre inventivo e renovador.

\section{O design estratégico como metodologia articuladora e a autonomia da ação}

Ação, discernimento e estratégia são termos recorrentes na cultura de projeto de design; multiplicam-se, também, nas metodologias que desenvolvem o design contemporâneo ou a pesquisa em design. Acredita-se, entretanto, que uma das correntes do design que favorece a percepção do potencial do paradigma da complexidade seja o design estratégico, já que ele privilegia uma reflexão metaprojetual em seus projetos e se caracteriza pelo seu foco na processualidade. Nela, o foco sai da finalização dos produtos ou dos serviços e vai para o processo, que então passa a atualizar-se constantemente, desenvolvendo-se com as inovações tecnológicas, adaptando-se aos ambientes, remodelando-se mediante as interações com os sujeitos, enfim, adquirindo um caráter vivo e mutante. O design estratégico se empenha em renovar seus processos, a fim de contribuir com inovações sociais de todos os tipos, seja em produtos ou em serviços. Seus projetos estão comprometidos com uma visão crítica de mundo que projeta cenários futuros e que, ao encontrar a realidade, buscam preservar o princípio da incerteza e se utilizam de estratégias no curso das ações para lidar com os acasos. Muitos desses acasos se tornam insumos criativos. Um projeto que vive a sua processualidade, alimenta-se de estratégias e está em permanente diálogo com a ciência e com as experiências criativas, o que se refletirá nas suas produções.

O design estratégico praticado no Brasil, é proveniente de uma corrente italiana iniciada há cerca de 10 anos, por autores como Ezio Manzini, Francesco Zurlo, Flaviano Celaschi, entre outros. Essa corrente de pensamento surge como provocadora de reflexões sobre as mudanças sociais necessárias para potencializar o processo de transição, rumo a uma sociedade sustentável. É uma metodologia em construção, cuja proposta é a de um modelo organizacional efetivo e colaborativo, de criação cooperativa de uma base comum de conhecimento. Acredita-se que o seu maior diferencial está em priorizar a atitude metaprojetual de reflexão crítica sobre os processos existentes, no sentido de repensá-los, ressignificá-los e, por fim, redesenhá-los, com o intuito de reconhecer seus limites e transformá-los em oportunidades.

Para Bentz e Franzato (2016), pesquisadores que tem avançado os estudos dessa linha no Brasil, o design estratégico como método tem na sua centralidade os processos criativos projetuais, no qual os artefatos ou as realidades são compreendidas como ecossistemas criativos. Os autores chamam de 'traços conceituais' cinco questões relevantes que caracterizam e dão forma a esse tipo de processo. A primeira delas diz respeito à pluralidade de atores em ação cooperativa e colaborativa; a segunda, à tangibilidade/intangibilidade nos percursos criativos; a terceira, à inclusividade nas circunstâncias exógenas/endógenas; a quarta, à pluridiversidade nas relações propostas; abertura para o desenvolvimento ou não de dado elemento; e, por fim, a quinta diz respeito à sistemicidade nas relações entre todos os termos envolvidos. Esses traços conceituais têm relação direta com a teoria da Complexidade. 
Bentz e Franzato (2016) ressignificam o processo projetual de design pela visão do design estratégico, no qual se destacam as múltiplas relações instauradas na ação projetual e concebem as competências técnicas de design como plataformas transdisciplinares que suportam a convergência de especialistas e dos demais atores que integram o que é chamam de 'produtiva rede de colaboração'. Para eles "o processo de design resulta em um percurso para elaborar, exercitar e então, fazer evoluir as estratégias organizacionais" (BENTZ \& FRANZATO, 2016, p.1421). Por essa definição, acredita-se que esse tipo de processo de design tão poderoso nas relações, poderia transformar qualquer outro processo de design, inclusive o de produtos. Os autores referenciados, fundamentam que o design estratégico ao evocar uma atitude reflexiva/metaprojetual, seria capaz de inovar e criar valor.

Dessa forma, a articulação do conceito de programa e estratégia, como está sendo proposta neste artigo, acontece num processo de design estratégico em uma instância 'metaprojetual', que, por sua vez, refletirá diretamente sobre as ações desencadeadas na realidade. Esta instância metaprojetual (meta) está conectada por meio dos níveis de conhecimento ${ }^{3}$, com o nível metodológico (meta, meta), onde se encontra o design estratégico, e epistemológico (meta, meta, meta), onde está a teoria da complexidade. Essa seria a articulação promovida pela ciência nova, conectando conhecimentos do macro ao micro e, com isso, produzindo efeitos na realidade por meio do desencadeamento de ações. Ao promover essa reflexão crítica multinível, de como pensar e conduzir os processos de design, abre-se espaço para renovar as metodologias a partir da mudança de visão de mundo, no presente caso, por meio de uma abertura à teoria da complexidade.

A importância de trazer à discussão e fundamentar conceitos como o de estratégia e programa em níveis de conhecimento pela teoria da complexidade, é fazer frente à disseminação de sua utilização corriqueira e até imprudente, como termos clichês que beneficiam mais uma ação de marketing do que conferem o devido peso à atitude crítica-reflexiva por parte dos projetistas. Manzini (2017) por exemplo, defende uma mudança no papel dos designers, a partir dessa necessidade explícita de redesenharem-se a si mesmo e aos modos como operam. Tal posição não significa o abandono dos saberes ou a perda de suas competências já acumuladas pelo design ao longo da história, mas, sim, a sua transformação. Para o autor "o designer expressa suas habilidades através da resolução de problemas e da produção de sentido" (MANZINI, 2017, p. 17) e é, nessa última, que ele pode dar a sua contribuição mais significativa. Essas operações seriam enriquecidas significativamente, se o design considerasse que a complexidade, presente na vida cotidiana e nos papéis sociais do sujeito, pode ressignificar noções como a de usuário, por exemplo. Como defende este artigo, se o designer compreender tal potencial, poderá projetar para os sujeitos e, por conseguinte, provocar significativas e profundas mudanças em seus processos projetuais, no âmbito da ação, do discernimento e da estratégia.

Entretanto, seja qual for a metodologia adotada, sabe-se que ela é uma desencadeadora de ações. Apesar dos processos de design serem historicamente marcados pela clareza do problema de pesquisa e pela busca de regularidade e previsibilidade das suas etapas, a ecologia da ação trazida pela complexidade aborda também uma questão muito vivenciada pelos projetistas que é a autonomia da ação e seus efeitos não previsíveis. Em relação à essa questão, Morin (2015a,

\footnotetext{
3 Se faz referência aqui ao "modelo dos níveis" de Bentz e Franzato (2016).
} 
p.101) explica que, contrariando a vontade do ator "a ação voluntária escapa quase imediatamente à vontade; foge, começa a copular com outras ações em profusão e volta, às vezes desfigurada e desfigurante, à cabeça do seu iniciador”. A ecologia da ação alerta para se considerar os riscos enormes da ação. Tais riscos podem ser externos que se tornam internos (na complexidade, unos), uma vez que a ação pode derivar, ou até inverter, a sua finalidade, sem que o atuante tome consciência disso. Continuaria a agir, com toda boa vontade, no sentido contrário ao seu querer. Morin (2015a) ainda adverte que é preciso desconfiar da crença que a ação opera logicamente no sentido do seu projeto, ou seja, esta ação pode entrar no jogo das finalidades inimigas. Assim, nem sempre as intenções de um projeto que vise à promoção do bem-estar, por exemplo, organizam-se para tanto, não só pelas ações contrárias que podem atingi-lo, como pela polissemia do termo bem-estar que responde a vários significados.

Com isso, pode-se definir que a ação é, antes de tudo, jogo ecologizado, ou seja, um sistema de relações sustentáveis. Para evitar que a ação se distancie completamente do seu iniciador, é preciso incessantemente segui-la, alcançá-la, corrigi-la. Trata-se de uma corrida desenfreada, em que a ação, finalmente, se distanciará do perseguidor e irá perder-se no amálgama das interretroações. Se o processo for aberto para ideias ecológicas de inter-retroações, de eventualidades e de riscos, poderá concentrar-se no problema central da ação, que é a estratégia, e a ecologia da ação poderá enriquecer a etologia (comportamento) da ação. Em processos de design, a estratégia permite prever um certo número de cenários para a ação, cenários que poderão ser modificados, segundo informações que chegarão no curso da ação e segundo os acasos que vão ocorrer e perturbar a ação. Ao agregar a certeza e a incerteza, a probabilidade e a improbabilidade como relevantes nas operações projetuais, os processos de design, então, serão menos enriquecidos pelos programas em si do que pelas estratégias.

\section{Considerações finais}

Este artigo de caráter exploratório apresenta uma reflexão que integra uma pesquisa maior em andamento e buscou trazer e contextualizar as principais ideias da teoria da complexidade para área do design por meio de uma revisão bibliográfica. Também teve como objetivo provocar (se não inspirar) uma abertura para que outros estudos avancem em direção à construção da "ciência nova" e das inúmeras possibilidades de reorganização do conhecimento. A sua contribuição concentrou-se em aprofundar conceitos primordiais para o design, como o de estratégia e programa no contexto do pensar e do agir projetual. Para isso, precisou recorrer a outras noções relevantes como a de sujeito, sistema, ecossistema e ecologia da ação em uma perspectiva transdisciplinar. Pode-se concluir que a teoria da complexidade é uma fonte de ideias e conexões criativas para o design enriquecer os seus processos e muitos estudos ainda podem avançar nesse sentido.

A relevância dessa reflexão se deu pela crença de que um processo de design, principalmente o estratégico, deva envolver inventividade nas formas de conexão dos saberes (transdisciplinaridade) e confiança no pensamento abdutivo, não só no dedutivo e indutivo. Mostrou que é preciso dominar e defender essas ideias fundantes, em todos os níveis de conhecimento, para aventurar-se a inovar no processo e, por consequência, essa inovação possa vir a se refletir no que for produzido. Só assim é que o processo de projeto poderá se transformar 
em uma instância de operação de inteligência, de sensibilidade e de produção de conhecimento, para além do já sabido e codificado.

O processo que a complexidade pôde iluminar no design é aquele autopoiético, que traz consigo a noção da inteligibilidade do sistema e de autonomia criativa. O design, ao encarar a metodologia como uma desencadeadora de ações, ganha e perde poderes ao mesmo tempo. Perde a ideia do 'controle absoluto', do conhecimento em todas as suas etapas, mas ganha no potencial criador e inventivo, por meio da condução de suas estratégias na ação. O diferencial do designer que compreende o projeto pelos ideais da complexidade, é que, ao abrir espaço para incerteza e se interessar pelos movimentos produzidos pelo próprio sistema, se depara com uma infinidade de possibilidades que podem responder, de inúmeras maneiras, às questões do projeto. Ou até mesmo, como não raro acontece, pode levantar novas questões mais relevantes do que as que estavam pautadas no início do projeto. Acredita-se que os processos de design sejam eles voltados para o coletivo, seja para produtos, precisam ter esse olhar ecológico para revelar novas relações ou ideias inspiradoras.

O agir projetual, portanto, navega em mares caudalosos, ou seja, a estratégia e o conhecimento percorrem um oceano de incertezas entre arquipélagos de certezas, movidos pela prudência e pela audácia, simultaneamente. Estratégias orientam a tomada de decisões e estabelecem compromissos, sempre passíveis de serem descumpridos pelas retroações que se apresentam ao longo dos processos. Sendo assim, é possível imaginar que a presença de dualidades simultâneas não requer a anulação de uma ou de outra, ao contrário, é sua potencial presença que estimula a ação criativa nos processos de design.

$\mathrm{O}$ processo de design, quando deixa a sua instancia metaprojetual para projetar, inicia o percurso das ações. Essas ações, vistas pelo olhar ecológico ecossistêmico, tem como elemento central a estratégia. Assim, nessa perspectiva, o design, ao projetar fundado na complexidade, deve ter em mente o permanente arranjo e mutação dos ecossistemas considerados. O inesperado, o imprevisto aliado às estratégias, pode ser chave que liberta os desejos e estimula invenções e inovações.

\section{Referências}

ALEXANDER, Christopher. Notes on the Synthesis of Form. Seventh Printing. Cambridge, Massachusets: Harvard University Press, 1973. 216p.

ALEXIOU, Katerina; JOHNSON, Jeffrey; ZAMENOPOULOS, Theodore. Embracing complexity in design. London: Routledge, 2009. 232p.

BENTZ, Ione; FRANZATO, Carlo. O metaprojeto nos níveis de design. Blucher Design Proceedings, v. 2, 9, p. 1416-1428, 2016.

CROSS, Nigel. A history of design methodology. Design methodology and relationships with science, p. 15-27, 1993.

CROSS, Nigel. Engineering design methods: strategies for product design. Chichester: John Wiley \& Sons, 2008. 217p.

GREGORY, Sydney A. Design science. In: The design method. Boston: Springer, 1966. p. 323-330. 
JONES, J. Christopher. Design methods. New York: John Wiley \& Sons, 1992. 407 p.

MANZINI, Ezio. Design: quando todos fazem design: uma introdução ao design para a inovação social. São Leopoldo: UNISINOS, 2017. 254 p.

MATURANA, Humberto. R.; VARELA, Francisco. J. Autopoiesis and Cognition. The Realization of the Living. Boston Studies in the Philosophy of Science New York, New York, v. 42, p. 1- 146, 1980.

MORIN, Edgar. Complexidade humana. Novos Paradigmas, cultura e subjetividade. Porto Alegre: Artes Médicas, 1996. 294 p.

. Introdução ao pensamento complexo. Porto Alegre: Sulina, 2005. 120 p.

2000. $263 \mathrm{p}$

; LE MOIGNE, Jean-Louis. A inteligência da complexidade. São Paulo: Petrópolis, O método 1: a natureza da natureza. Porto Alegre: Sulina, 2016. 477 p.

. O método 2: a vida da vida. Porto Alegre: Sulina, 2015a. 527 p.

. O método 3: o conhecimento do conhecimento. Porto Alegre: Sulina, 2015b. 286 p.

Os sete saberes necessários à educação do futuro. São Paulo: Cortez, 2006. 118 p.

PRIGOGINE, Ilya. O fim das certezas: tempo, caos e as leis da natureza. São Paulo: UNESP, 1996. $202 \mathrm{p}$.

SIMON, Herbert A. The sciences of the artificial. Cambridge: MIT, 1999. 231 p.

\section{Sobre os autores}

\section{Danielle Difante Pedrozo}

Doutoranda em Design Estratégico (UNISINOS) com período sanduíche na Libera Università di Lingue e Comunicazione (Milão/IT) e bolsista CAPES. Professora Assistente do Departamento de Desenho Industrial UFSM. Mestre em Design da Comunicação pela Nuova Accademia di Belle Arti di Milano (Milão/IT). Bacharel em Desenho Industrial - Programação Visual e Comunicação Social - Publicidade e Propaganda, ambas pela Universidade Federal de Santa Maria - UFSM.

https://orcid.org/0000-0002-8152-8231

\section{Ione Maria Ghislene Bentz}

Doutora em Linguística e Semiótica pela USP, Estágio Pós-doutoral Paris -Sorbonne, professora, pesquisadora e orientadora no Programa de Design - Mestrado e Doutorado na UNISINOS, desenvolve pesquisa em Crítica às teorias de design e em Processos de Significação e Comunicação em projetos de design. Atua na condução de seminários de estudos avançados e na liderança de Grupos de Pesquisa.

https://orcid.org/0000-0002-9149-5701 